\title{
The Role of Managers in Handling Information Overload in The Information Society Era: A Case Study of GCB Bank, Ghana
}

\author{
Prince Kelvin Owusu \\ Ghana Technology University College, Information Systems Department, Ghana. Email: powusu@gtuc.edu.gh
}

DOI: $10.46382 / M J B A S .2020 .4301$

The main purpose of the study is to assess the role of managers in managing information overload in this information age era. The study also intended to specifically achieve the following identified objectives: to ascertain the causes of information overload in organizations in the financial sector and assessed the relationship between information overload and decision making of managers of organizations in the financial sector. The method utilized for this investigation is the descriptive research design. The technique for data analysis was by the utilization of content analysis. In relation to the causes of information overload in organizations in the financial sector, it was basically found that work interruption and work time pressure but the amount of information, organizational design; the nature of information (e.g. the level of ambiguity, novelty and complexity); the person involved in handling the information (e.g. attitude, qualification and experience); tasks or processes to be completed (e.g. frequency of reoccurrence); and the use or misuse of information technology like the internet, social media and e-mail are also causes of information overload. The study discovered that when information overload happens and the capacity to make decision is declined and, in this way, the additional data cannot be processed properly and just meddles the capacity to decide for the firm. With respect to the role of managers in managing information overload in this information era, the study essentially uncovered that found that managers will in general adapt to this idea at individual level, by utilizing a blend of separating, withdrawal and summing up techniques. The study concluded that managers have the role to filter any information to identify any information gaps in order to make good decisions for the improvement of performance in the organization. The study also recommended that managers should not overlook information overload in their organizations especially in this information age era, but needs to make sure that any information received are correctly checked and filtered in such a way that they might aid in making good decisions.

Keywords: Information overload, Information management, Information fatigue syndrome, Information society, Web technologies.

\section{Introduction}

The society today is all about information and the one who has access to quality information has the power. Information has become the main thrust of many people's lives and the world that once, during the time of industry, was governed by normal sources, is presently run by data that appears to be unbounded. To get by in the working environment or just to work in the public sector, we are obliged to acclimatize a colossal measure of data. This is valid in research where data is the life-blood of mechanical innovative work and the employee may feel overpowered by the size and flow of data while he or she endeavors to stay up to date with his field (Brown and Duguid, 2017). It is therefore very critical for managers to enhance their roles in managing information overload in their organizations to help in making good decisions for employees and the firm at large. Although innovation helps society to carry out their responsibilities well and quicker, at times this has few traps, which assume a primary job in causing information overload (Benselin and Ragsdell, 2016).

Today, organizations or businesses will struggle to gain competitive advantage in the industry it operates without having access to quality information. Because information is so vital to the survival of any business today, huge volumes of these are generated each day. Hence, there is the challenge of handling the vast volume of these information which is termed as information overload in our offices and businesses which GCB bank Ghana, is no exception. Information overload can be said to be the condition of having an excessive amount of information at ones disposure that he or she cannot think properly (Altay\& Labonte, 2014), and this has become a style of life for some managers today. In the event that managers are busy working at the office, they are ignited with 
messages, voice messages, SMSs (Short Message Services), and electronic mails which are all befuddling their thoughtfulness regarding the undertaking or work they are doing. Information overload can also be basically referring to the volume of information exchanged in the workplace as well as the poor quality (irrelevant information) of information shared with employees (Zhuang, Qiu, and Peng, 2011). To have so much availability of information, obviously it has benefits, yet it very well may be counterproductive on the off chance that it keeps managers from achieving things they truly need to do in the course of a day, and consequently keeps us from using sound judgment (Dean \& Webb, 2011). Overload of information is viewed as one of the negative results of the era of information age that happens when information got turns into an obstruction as opposed to an assistance, or it happens when the transmission of new information surpasses the recipient's capacity to process (Bettis-Outland, 2012). What is more, is when managers begin to think that it's progressively hard to adapt to all the new information they get, changes in the firms and advancements in technologies they use, and progressively mind boggling and eccentric reactions of their activities. This for sure prompts developing postponement in making decisions or even wrong choices which eventually affect the organization (Davis, 2011).

In these current years of the information age, overload of information is experienced as diverting and unmanageable data, for example, email spam, email notices, texts, Tweets and Facebook updates with regards to the workplace (Whelan and Teigland, 2010). Subsequently, a break from such data adversely influences the consideration of directors. It can take as much as twenty-five minutes before the administrators comes back to their allotted assignments in the wake of review an email or any other information (Peñalvo, Palacios and Hsu, 2013). It is along these lines enlightening to take note of that except if information overload is comprehended and overseen well, it can be a basic data issue which keeps managers from executing out their assignments adequately. Information overload is an unequivocal variable driving negative workplaces that are reducing efficiency, hosing innovativeness, and making individuals despondent (Dean and Webb 2011). Overload of information happens when leaders face a degree of information that is more noteworthy than their information processing limit, which is an excessively high load of information (Jackson and Farzaneh, 2012), however the wonder isn't kept to the contemporary world. As Blair (2012) noted in her journal she reviewed that, even in the thirteenth century, researchers whined of 'the key elements of the sentiment of information overload which are still with us today; the huge number of books, the brevity of time and the caginess of retention (Blair 2012, p. 1). With the increasing processing power and reducing costs of multimedia technologies, society power to universally access and disseminate information continues to become indeterminately easier. Nevertheless, emerging research indicates that society is finding it difficult to process information as fast as they land (Whelan \& Teigland, 2011). The problem of information overload is highly seen today. Whether or not managers actively seek information, they are bombarded with it since we are living in an 'information society' so this seeks to address these questions: What are the causes of information overload in organizations especially the financial sector? (b) What is the relationship between information overload and decision making of managers in organizations today?

Even though the issue has been recognized, there is clashing conclusion with respect to the degree of the issue of information overload (Paul and Nazareth, 2010). Some contend that the genuine issue concerning management of 
information is, for example, missing data, late or muddled data. There are five components which considered as the primary driver for the issue of information overload which include the data itself (its amount, recurrence or power, and quality or general attributes); the individual getting, preparing or imparting data; the assignments or procedures which should be finished by an individual; team or the firm, the organizational plan or design (i.e., the formal and casual work structures) and the data innovation that is utilized (and how it is utilized) in an organization (Blair, 2012).

The issue of information overload and approaches to oversee it have been the focal point of an extraordinary number of studies, since it adversely influences the managers' profitability, execution of responsibilities, and their capacity for deciding. However, none of these studies have been conducted in the financial sector of Ghana especially with respect to the banking industry which GCB bank is no exception. It is in view of this, the study seeks to assess the role of managers in managing information overload in this information society era.

\section{Literature Review}

\section{A. Concept of Information Overload}

The idea of information overload is established in concepts of human data processing. Mill operator (1956) proposed "chunking" to depict how individuals hold a limited quantity of new data in their psyches for a brief timeframe. A piece of data alludes to a unit of the material being introduced, which can fluctuate from digits, words, and text to chess positions and individuals' faces (McCauley and Christiansen, 2015). At the point when people get a bit of new data from the outside setting, they will separate the data into significant units as indicated by its attributes, hold it in transient memory, and afterward sort out and control it to create a reaction or settle on a choice (Denstadli, Lines and de Dios Ortúzar, 2012). Past studies has demonstrated that short term memory has constrained capacity limit: it can hold just five to nine unmistakable lumps of data (seven give or take two) for close to 30 seconds one after another (Singh, Spitzmueller, Petersen, Sawhney and Sittig, 2013). In this way, individuals' capacity to see and react to new data is additionally limited (Shrivastav \& Hiltz, 2013).

As various controls approach overload of information from alternate points of view, there is no single commonly acknowledged definition (Hoq, 2014). All things considered, the idea of information overload envelops three principal components: the amount of data that should be incorporated to finish an assignment, the person's data handling limit and the measure of time distributed to the undertaking (Koroleva, Krasnova and Günther, 2010). As indicated by Meyer (1998) referred to in Eppler (2015), overload of information alludes to circumstances where the volume of data introduced surpasses a person's intellectual limit with respect to processing of the information. Wilson (1996) referred to in MacDonald, Bath and Booth (2011) characterized the concept as an excess of significant data or being troubled with over the top measures of spontaneous data that can't be acclimatized because of an absence of time. At the end of the day, information overload happens when people need more an ideal opportunity to process pertinent data regardless of whether they know about its quality (Fukukura, Ferguson \& Fujita, 2013). In recent study it was indicated that $56.2 \%$ of UK employees said that their work is negatively impacted by the huge volume of data they must process at work (Speier, Valacich, and Vessey, 1999). Again, $91 \%$ 
of US employees admitted that they sometimes delete or discard work-related information without fully reading it (Shrivastav \& Hiltz, 2013). The issue here is most employees have to deal with excessive amounts of information and data every day at work. Expectedly this kind of issues come at a cost, that is information overload costs the US economy a minimum of $\$ 900$ billion per year in lowered employee productivity and reduced innovation, Basex, (2012).

\section{B. Causes of Information Overload in Organizations}

Whatever the estimation of the substance is a part of the issues that includes the steady interferences experienced. When reacting to an email message that springs up on our screen or to the vibration of our cell phone while getting a SMS from a companion, at that point it is not simply to invest energy perusing the message. It is likewise how to recuperate from the interference and pull together our consideration (Benselin and Ragsdell, 2016). The quick pace of the present innovation, Personal Computers (PC) has become so amazing that they can create, control and spread data quicker than individuals can process. Besides, the huge volume of data that undermines their consideration regularly habitually makes many lose control of the circumstance (Swar, Hameed and Reychav, 2017).). Then again, with PC processing speed multiplying like clockwork in the course of recent years (Blummer and Kenton, 2014), an excess of data originating from an excessive number of sources by means of electronic methods has brought about its helpfulness lessening quick as a huge extent of it couldn't be appreciated a handled in time. As needs be five reasons for overload of information have been distinguished, to be specific: (Ayyagari, 2012) organizational design; the idea of data (for example the degree of uncertainty, curiosity and multifaceted nature); the individual associated with taking care of the data (for example disposition, capability and experience); undertakings or procedures to be executed (for example recurrence of reoccurrence); and the utilization or abuse of data innovation like the web, social media and email. Mulling over the elements that add to the impression of information overload, there are a few elements, summed up into four gatherings: (Meister and Koch, 2012) progressively various and expanding measures of accessible data; impact of new data and correspondence innovations. changing nature of work with the new accentuation on interdisciplinary and synergistic work which both require more noteworthy correspondence and clients currently look for data as opposed to a representative.

\section{Relationship Between Information Overload and Decision Making of Managers of Organizations}

Leaders' everyday undertakings progressively include the utilization of PCs and a large number of the ongoing advancements in data growth have additionally exacerbated the quantity of interferences that happen in the workplace (Speier, Valacich, and Vessey, 1999). Presence of dull and wrong data some way or another makes the supervisors frustrated and forestalls them arriving at the helpful information. The more helpful data exists, the more investigation is required and here and there the over the top examination leads in loss of motion and hurt the precise decisions (Floridi, 2013). True to form, people who have almost no data for handling settle on unprofitable choices. At the point when the data sum is expanded, the data handling and the dynamic quality is expanded as well. In any case, the manager could approach more data by deciding a point instead of by the information processed. Presently, the enlightening information overload happens and the capacity to make decision is declined 
and, in this manner, the additional data cannot be prepared and just meddles the capacity for making decisions (Nejadirani and Rajabzadeh, 2011).

Overload of information happens when the measure of contribution to a framework surpasses its limit of processing. Leaders have genuinely constrained intellectual limit of processing. Subsequently, when information overload happens, almost certainly, a decrease in choice quality will happen. Studies from various orders has found, for instance, that overload of information diminishes the quality for making decisions, builds the time required to settle on a choice, and expands disarray in regard to the choice (Oldroyd and Morris, 2012).

\section{Theoretical Review}

The study is basically underpinned on the information theory. Information theory further extends the concept of information overload by focusing on information transmission. Information theory is articulated in the works of Shannon [Shannon \&Weaver, 1949, 1963]. In general, it is a formal mathematical theory that provides an extremely rich apparatus for formalizing information transmission and communication.

Transmission of information and the limit of correspondence channels are the key ideas of the theory of information. The individual is contrasted with a traditional data channel, characterized as far as transmitting limit and transmission capacity. It is contended that at each purpose of time four unique bunches of data can be recognized: data that is introduced by a boost; data introduced; accordingly, transmitted data and lost data (Bylicka, Chruściński and Maniscalco, 2014). As the measure of data introduced by the upgrade builds, the measure of data transmitted does not increment in a similar extent, however, asymptotically moves toward a value of threshold. The motivation behind why data transmission reduces as the measure of data goes up is the restricted transmitting limit of the channel. Because of multidimensional decisions, measurements can be delegated either symmetrical or corresponded. For the related measurements, the level of excess fluctuates from zero to one. The more noteworthy the quantity of symmetrical measurements transmitted; the more prominent will be the general data transmitted. Simultaneously, the more prominent the quantity of associated low excess measurements transmitted, the less will be the data misfortune (Gohari, Mirmohseni and Nasiri-Kenari, 2016). Two psychological assets are engaged with handling of information, for example, consideration and working memory. They characterize the data handling limit of human and are carefully restricted. Extra strain is forced when the intellectual assets must be separated among a few assignments. Normally, the maximal performance is acquired when every psychological asset is given to one specific assignment. Performance drops fundamentally when the intellectual assets must be shared among the various assignments. In this manner, the issue of distribution of intellectual assets becomes essential (Tishby \& Polani, 2011).

\section{E. Empirical Review of Related Studies}

Saxena and Lamest (2018) found that the volume and pace combined with the subjective and spontaneous nature of data caused information overload to directors. To adapt to this idea at individual level, directors utilized a blend of separating, withdrawal and summing up methodologies. At the level of the firm, the act of summing up advanced into improvement and utilization of intuitive dashboards. 
The reason for MacDonald, Bath, and Booth (2011) was to acquire knowledge into supervisors' decision-making undertakings in UK when tested by unseemly data quality, and to test structures created from studies to see whether they apply to these administrators. The discoveries of the investigation were that the administrators would in general satisfice (end the hunt procedure and settle on a sufficient choice, while perceiving that gaps in the remaining information). Those tested by too little data seem to fit portrayals of data neediness, while others depicted parts of overload of information

As per Iqbal, Shahi and Khan, (2012), the individuals who are over-burden with data regularly neglect to contemplate the future, basically in light of the fact that they have no manners of thinking accessible past the instantaneous concerns. With so much data flooding into their cognizance, it tends to be difficult to think ahead and plan as per the particular data accessible, and this is the primary explanation that influence contrarily the decision-making procedure. Skaik, (2014) showed noteworthy relationship of overload of information with the managers' procedure in making decisions. The investigation suggested that the impacts of overload of information ought not be disregarded and to stay up with the most recent advancements in the realm of data innovation and interchanges to encourage defeat of information overload. Also, the firms were encouraged to employ authorities in data the executives and recruiting staff on the best way to manage overload of information. Likewise, it was prescribed to comprehend the marvel of overload of information that ought to be a piece of the training of the managers and instruction programs particularly for the individuals who are distinguished as being in danger of encountering overload of information. $\mathrm{Li}$ and $\mathrm{Li}$ (2011) proposed a reasonable model and some operational factors, where overload of information is as a mediating variable between the elements of causes and effects. The examination proposes that work proficiency and work quality are both not unequivocally associated with overload of information. The examination likewise found that the fundamental driver of overload of information are the work interference and work time pressure yet the measure of data.

\section{Research Methodology}

The study utilized for this investigation is the descriptive research design. The researcher picked descriptive research design because of the reality the examination is worried about specific expectations, portrayal of facts and qualities concerning people and organizations (Schwartz-Shea \& Yanow, 2013). The descriptive research design is the kind of designs that guarantees rigidity nature and spotlights on the segments of the objectives of the study. The study utilized the descriptive research design. The researcher picked descriptive research design because of the reality the examination is worried about specific expectations, portrayal of facts and qualities concerning people and organizations (Schwartz- Shea \& Yanow, 2013). The descriptive research design is the kind of designs that guarantees rigidity nature and spotlights on the segments of the objectives of the study. Data were gathered from managers of the selected GCB bank Ghana and through interviews and were analyzed using the content analysis technique.

Content analysis. This is what was utilized to break down the objectives of this research due to the kind of data to be dissected, which was secondary data. The study likewise guarantee that the previously existing written works are based on by the utilization of content. 


\section{Discussion of Findings}

\section{A. Causes of Information Overload in Organizations in the Financial Sector}

In relation to the causes of information overload in organizations in the financial sector, analysis was conducted with the use of content analysis technique. With this in place, it was basically found that work interruption and work time pressure, but the amount of information were causes of information overload in organizations ( $\mathrm{Li}$ and Li 2011). Apart from these, it was also discovered that organizational design; the nature of information (e.g. the level of ambiguity, novelty and complexity); the person involved in handling the information (e.g. attitude, qualification and experience); tasks or processes to be completed (e.g. frequency of reoccurrence); and the use or misuse of information technology like the internet, social media and e-mail are also causes of information overload (Ayyagari, 2012).

\section{B. Relationship between Information Overload and Decision Making of Managers of Organizations in the}

\section{Financial Sector}

The study discovered that when information overload happens and the capacity to make decision is declined and, in this way, the additional data can't be processed properly and just meddles the capacity to decide for the firm (Nejadirani and Rajabzadeh, 2011). Skaik, (2014) likewise showed noteworthy relationship of information overload with the supervisors' procedure of making decisions. Despite what might be expected, Iqbal, Shahi and Khan, (2012) demonstrated that when data is overwhelmed into the cognizance, it tends to be difficult to think ahead and plan as indicated by the especially data accessible, and this is the primary explanation that influence adversely the procedure in making decisions.

\section{Role of Managers in Managing Information Overload in this Information Age Era}

With respect to the role of managers in managing information overload in this information era, the study essentially uncovered that found that managers will in general adapt to this idea at individual level, by utilizing a blend of separating, withdrawal and summing up techniques. At the level of the firm, the act of summing up advanced into improvement and utilization of intuitive dashboards (Saxena and Lamest (2018). Also, managers would in general satisfice (end the pursuit procedure and settle on an adequate choice, while perceiving that remaining information gaps). Those tested by too little data seem to fit depictions of data neediness, while others portrayed parts of information overload.

\section{Conclusion}

The problem of information overload is widely recognized today. Living in an information society, we are bombarded with information whether or not we actively seek it. We are all affected by the increasing number of sources from which information emanates. Despite these happenings, managers need to find ways and means of making sure that these information overload do not influence their decision making as well as the performance of the employees and the organization at large. In assessing the role of these managers in managing information overload, the concludes that managers have the role to filter any information to identify any information gaps in 
Mediterranean Journal of Basic and Applied Sciences (MJBAS)

Volume 4, Issue 3, Pages 01-09, July-September 2020

order to make good decisions for the improvement of performance in the organization. In view of this, it is therefore recommended that managers should not overlook information overload in their organizations especially in this information age era, but needs to make sure that any information received are correctly checked and filtered in such a way that they might aid in making good decisions. In addition, organizations need to create an information management unit under their technological department and recruit an abled officer for such responsibilities in order to free the manager from such responsibilities.

\section{References}

Altay, N., \& Labonte, M. (2014). Challenges in humanitarian information management and exchange: evidence from Haiti. Disasters, 38(s1), S50-S72.

Ayyagari, R. (2012). Impact of information overload and task-technology fit on technostress. In Proceedings of the southern association for information systems conference (pp. 18-22).

Benselin, J. C., \& Ragsdell, G., (2016). Information overload: The differences that age makes. Journal of Librarianship and Information Science, 48(3), 284-297.

Bettis-Outland, H. (2012). Decision-making's impact on organizational learning and information overload. Journal of Business Research, 65(6), 814-820.

Blair, A. (2012). Information Overload. History of Ideas, 64(1), 11-28.

Blummer, B., \& M. Kenton, J. (2014). Reducing patron information overload in academic libraries. College \& Udergraduate Libraries, 21(2), 115-135.

Brown, J. S., \& Duguid, P. (2017). The social life of information: Updated, with a new preface. Harvard Business Review Press.

Bylicka, B., Chruściński, D., \& Maniscalco, S., (2014). Non-Markovianity and reservoir memory of quantum channels: a quantum information theory perspective. Scientific reports, 4(1), 1 -7.

Davis, N. (2011). Information overload, reloaded. Bulletin of the American Society for Information Science and Technology, 37(5), 45-49.

Dean, D., \& Webb, C. (2011). Recovering from information overload. McKinsey Qly, 1(1), 80-88. Denstadli, J. M., Lines, R., \& de Dios Ortúzar, J. (2012). Information processing in choice-based conjoint experiments. European Journal of Marketing.

Eppler, M. J. (2015). 11 Information Quality and Information Overload: The Promises and Perils of the Information Age. Communication and technology, 5, 215.

Floridi, L. (2013). The ethics of information. Oxford University Press.

Fukukura, J., Ferguson, M. J., \& Fujita, K. (2013). Psychological distance can improve decision making under information overload via gist memory. Journal of Experimental Psychology: General, 142(3), 658. García Peñalvo, F. J., Colomo Palacios, R., \& Hsu, J. Y. J. (2013). Discovering knowledge through highly interactive information-based systems.Gohari, A., Mirmohseni, M., \& Nasiri-Kenari, M. (2016). Information theory of molecular communication: Directions and challenges. IEEE Transactions on Molecular, Biological and Multi-Scale Communications, 2(2), 120-142. 
Hoq, K. M. G. (2014). Information overload: Causes, consequences, and remedies - A study. Philosophy and progress, $49-68$.

Iqbal, J., Shahi, A., \& Khan, A. (2012). Decision Making in Organizations. Interdisciplinary Journal of Contemporary Research in Business, 4(3), 660-677.

Jackson, T. W., \& Farzaneh, P. (2012). Theory-based model of factors affecting information overload. International Journal of Information Management, 32(6), 523-532.

Koroleva, K., Krasnova, H., \& Günther, O. (2010).'Stop spamming me!': exploring information overload on Facebook.

Li, T., \& Li, M. (2011). An investigation and analysis of information overload in manager's work. iBusiness, 3(1), 49-52.

McCauley, S. M., \& Christiansen, M. H. (2015, July). Individual Differences in Chunking Ability Predict On-line Sentence Processing. In CogSci.

Meister, S., \& Koch, O. (2012). Information overload in telemedicine: using complex event processing and context for intelligent information filtering and supply. IFAC Proceedings Volumes, 45(4), 7-12.

MacDonald, J., Bath, P., \& Booth, A. (2011). Information overload and information poverty: challenges for healthcare services managers? Journal of Documentation.

Oldroyd, J. B., \& Morris, S. S. (2012). Catching falling stars: A human resource response to social capital's detrimental effect of information overload on star employees. Academy of Management Review, 37(3), 396-418.

Paul, S., \& Nazareth, D. L. (2010). Input information complexity, perceived time pressure, and information processing in GSS-based work groups: An experimental investigation using a decision schema to alleviate information overload conditions. Decision Support Systems, 49(1), 31-40.

Whelan, E., \& Teigland, R. (2010). Managing information overload: examining the role of the human filter. Available at SSRN 1718455.

Saxena, D., \& Lamest, M. (2018). Information overload and coping strategies in the big data context: Evidence from the hospitality sector. Journal of Information Science, 44(3), 287-297.

Shrivastav, H., \& Hiltz, S. R. (2013). Information overload in technology-based education: Ameta-analysis. Singh, H., Spitzmueller, C., Petersen, N. J., Sawhney, M. K., \& Sittig, D. F. (2013). Information overload and missed test results in electronic health record-based settings. JAMA internal medicine, 173(8), 702-704.

Skaik, S. A. S. (2014). the relationship between information overload and managers decision making process at interastional ncos in gaza strip. the relationship between information overload and managers decision making process at interastional ncos in gaza strip.

Swar, B., Hameed, T., \& Reychav, I. (2017). Information overload, psychological ill-being, and behavioral intention to continue online healthcare information search. Computers in Human Behavior, 70, 416-425.

Tishby, N., \& Polani, D. (2011). Information theory of decisions and actions. In Perception-action cycle (pp. 601-636). Springer, New York, NY. 